\title{
A Contribution to the Anatomical Study of the Mandibular Premolars
}

\author{
T.S.O. Capote $^{1} \quad$ R.A.A. Barroso ${ }^{1} \quad$ S.T.P. Pinto ${ }^{1} \quad$ M.B. Conte ${ }^{1} \quad$ J.A.D.B. Campos ${ }^{2}$ P.D.A. Bolini ${ }^{1}$ \\ M.A. Gonçalves ${ }^{1}$ \\ 1 Department of Morphology, Faculdade de Odontologia de \\ Araraquara, Universidade Estadual Paulista, UNESP, Araraquara, \\ Brazil \\ 2 Department of Food and Nutrition, Faculdade de Ciências \\ Farmacêuticas de Araraquara, Universidade Estadual Paulista, \\ UNESP, Araraquara, Brazil \\ J Morphol Sci 2018;35:58-63. \\ Address for correspondence T. S. O. Capote, Departamento de \\ Morfologia, Faculdade de Odontologia de Araraquara, Universidade \\ Estadual Paulista, UNESP, Rua Humaitá, 1680, CEP 14801-903, \\ Araraquara, SP, Brazil (e-mail: ticiana@foar.unesp.br).
}

\begin{abstract}
Keywords

- anatomy

- premolar

- dental crown

- dental education
\end{abstract}

\section{Introduction}

Normal shapes of the teeth, suitable arrangement on dental arch and natural occlusion are closely related to a functional performance and a physiological action. The shape of the tooth has an important role in masticating and protecting periodontal tissue. ${ }^{1}$ Knowledge of tooth morphology and function is fundamental to all aspects of dental practice, ${ }^{2}$ and it is essential to establish a correct diagnosis, to indicate the appropriate treatment and to avoid complications during received

July 17,2018

accepted

February 13, 2018
DOI https://doi.org/

10.1055/s-0038-1660493. ISSN 2177-0298.
Copyright $\odot 2018$ by Thieme Revinter

Publicações Ltda, Rio de Janeiro, Brazil
License terms

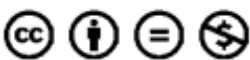


certain procedures like dental extractions, endodontic treatments, and surgical procedures. ${ }^{3}$

The discipline of Dental Anatomy is a component of the Basic Sciences in the program of Dentistry Schools ${ }^{4}$ that comprises the study and organization of the tooth as an isolated entity and as an integrant of both dental and masticatory systems. ${ }^{5}$ The professional (dental surgeon) who is committed to the preservation of human teeth should have a clear understanding of the characteristics and fundamentals of dental morphology. ${ }^{5}$ The learning process is mainly based on the identification of natural teeth, the study of stone or resin macro models, ${ }^{4,5}$ the computer-assisted learning program ${ }^{6}$ or even internet resources. ${ }^{7}$

Most dental anatomy textbooks describe the human dentition appropriately, but sometimes they fail in providing details, such as the variation in external root anatomy and internal root canal systems, as in the case of the mandibular first and second premolars. ${ }^{8}$ According to Kraus and Furr (1953), ${ }^{9}$ the mandibular first premolar shows an extremely wide range of morphologic variability. ${ }^{9}$ From all the teeth of the human denture, the first mandibular premolar is the most interesting morphologically. ${ }^{10}$

The first mandibular premolar is usually described as unirradicular, with an oval cross-section. ${ }^{11,12}$ However, there may be variability in root morphology, such as the presence of three roots and variation in the number of canals. ${ }^{3,8,13}$

As noticed relating to the roots of the mandibular first premolars, morphological variations in the dental crown of these teeth can also be observed. Kraus and Furr $(1953)^{9}$ published a relevant study about the morphology of the first mandibular premolars, describing seventeen different structures of the dental crown and the variations related to some of them, such as the number of lingual cusps, the position of the enamel ridge, and the grooves on the lingual surface. ${ }^{9}$

Dental anomalies involving the mandibular first premolars are rare, but they may occur, as in the case report of a 33year-old man who presented bilateral Dens invaginatus (dens in dente) that is a rare developmental anomaly resulting from invagination of a portion of the dental crown. It is an important dental anomaly, due to the possible pulpal involvement. ${ }^{14}$

There are few studies about premolar morphology, ${ }^{15}$ and the ones that exist do not study all the morphological characteristics, or use different methodologies. ${ }^{1}$

During the practical classes of Dental Anatomy, we can see some students with difficulties in identifying the first premolars, especially in determining the proximal surfaces. We can see the literature describing some features that may facilitate the identification of proximal surfaces of those teeth, although there are few studies in which researchers performed standardized measures, and provided more detailed information. According to Madeira and Rizzolo (2016), ${ }^{12}$ the distal occlusal fossa is the largest, and from both occlusal fossae (mesial and distal), the distal one is the closest to the lingual surface. These features may be facilitating the criteria for identifying the tooth's side. ${ }^{12}$ However, these characteristics are not routinely described in dental anatomy textbooks or in research papers.
The aim of this study was to evaluate the morphology of mandibular first premolars in young individuals, in which anatomical criteria were determined to identify the proximal surfaces, improving the anatomical study when those teeth were analyzed individually analyzed.

Therefore, it is expected that this study upgrades the published data about the mandibular first premolars, improving the identification of the hemi-arch of the individual mandibular first premolar, during morphological study in Dental Anatomy Classes.

\section{Materials and Methods}

This project was approved by the Ethics Committee of São Paulo State University (UNESP), School of Dentistry, Araraquara (CAAE 17513313.6.0000.5416).

A clinical evaluation was performed and it was based on 200 mandibular first premolars belonging to 100 students of São Paulo State University (UNESP), School of Dentistry, Araraquara, at the age of 18 to 25 years old, from both sexes.

As an inclusion criterion, individuals with healthy mandibular first premolars were evaluated. The analyses of individuals with those teeth with caries lesions, fractured and/or restored teeth, or with the mandibular first premolars absent were not included.

The following structures were evaluated: size of mesial occlusal fossa (MOF) and distal occlusal fossa (DOF) $(1=$ discreet; 2 = small; 3 = medium; 4 = large), occlusal fossa located closer to the lingual surface, presence/absence of grooves in the lingual surface that emerged from MOF and DOF, and from which proximal surface showed larger buccolingual dimension.

It was used a visual criteria for the classification of the occlusal fossae. Photographs of occlusal surface of mandibular premolars were made, and discreet, small, medium and large fossae were exemplified, in order that the examiner could follow those patterns during the analysis.

The buccolingual dimension of the proximal surfaces was also evaluated by visual criteria, without any metric instrument. The apexes of the buccal and lingual cusps were taken as reference points, and the distance from the apex of the buccal cusp to the apex of the lingual cusp was analyzed in the mesial and distal surfaces.

The analyses were made by a qualified examiner. For calibration of the examiner, the teeth were analyzed in duplicate, with an interval of at least 7 days between the analyses. From the 100 students who constituted the sample, 15 (30 teeth) were randomly selected. The minimum sample size was estimated considering a minimum agreement of 0.50 , power of $80 \%$ and $\alpha=5 \%$. The reproducibility was estimated using Kappa (k) Statistics when the data were dichotomous and Kappa statistic with linear weighting (kp) when the data were ordinal. It should be clarified that this step was necessary to ensure that evaluations were performed with an adequate accuracy.

To get the reproducibility of the two analyzes (initial and after interval), the measurements obtained from the initial evaluation were considered to compose the data of the study, 
since the other 85 students, who constituted the sample, were evaluated only once.

The associations of interest were estimated using Chisquare test or Fisher's exact test. The agreement between the categories of the anatomical structures of the teeth $(44 \times 34)$ was assessed using kappa statistic. The significance level was $5 \%$. To determine the number of teeth the rule of thumb was used, which recommends from 5 to 10 sample units per category of row and column variables. Therefore, considering that the test of association used in this study with the highest number of categories was $4 \times 4(=16)$, the minimum sample size should comprise from 80 to 160 teeth.

The criteria for identifying proximal surfaces of the mandibular first premolars were determined after the statistical analysis.

\section{Results}

From the 100 students, 80 were female. The intra-examiner reproducibility was performed in two different moments. Seven parameters were evaluated; four of them presented "Optimal" intra-examiner agreement (widest occlusal fossa, occlusal fossa closer to the lingual surface, proximal surface with the largest buccolingual dimension and groove from MOF; $\mathrm{K}=1.0$ ), and three presented "good" agreement (MOF, DOF, groove from DOF, ranging from 0.609 to 0.762 ) (Kappa -K).

The frequencies of the features observed in teeth 34 and 44 are presented in - Table 1. It can be observed that the size of most MOF for both teeth was "discreet" and "small," with no statistically significant difference between the teeth $(p=0.244)$. However, for DOF, the most frequent sizes were "small" and "medium," and there were no significant differences between the teeth ( $p=0.966)$. The widest occlusal fossa for both teeth was the distal one ( - Table 1; - Fig. 1).

For most of the evaluated teeth, the proximal surface with the largest buccolingual dimension was the distal surface, with no difference between the teeth $(p=1.0)$ ( - Table 1 ). We could observe that the distal surface presented a rounded configuration, whereas the mesial surface had a pointed contour, as if it presented two segments (-Fig. 1).

The occlusal fossa located closest to the lingual surface was also the distal fossa, however a high frequency of symmetrical occlusal fossae (44\% and $29 \%$ for 44 and 34 , respectively) was observed, with no difference between the teeth $(p=0.77$ ) ( - Table 1 ; - Fig. 2 ).

Grooves from MOF and DOF were not present in most individuals for 34 and 44 (-Table 1). - Table 2 presents the coincidences of each anatomical structure evaluated in 34 and 44 , in the same individual.

According to Kappa statistics, the agreement between 34 and 44 ranged from "weak" to "regular," except for the distal occlusal fossa that presented the "greatest" coincidence. Therefore, teeth 34 and 44 are not symmetrical, i.e, the size and morphology of the anatomical features assessed in the dental crown are not coincident on the right and left sides of the first mandibular premolars, in the same individual (-Table 2 ).

The frequencies of the anatomical features observed in 44 and 34 , according to sex, are presented in - Table $\mathbf{3}$. It can be
Table 1 Frequency of the anatomical features observed in teeth 44 and 34

\begin{tabular}{|c|c|c|c|}
\hline \multirow[t]{2}{*}{ Anatomical Features } & \multicolumn{2}{|l|}{$n$} & \multirow[t]{2}{*}{$\mathrm{p}$} \\
\hline & 44 & 34 & \\
\hline \multicolumn{4}{|l|}{ MFO } \\
\hline Discreet & 42 & 45 & \multirow[t]{4}{*}{0.244} \\
\hline Small & 54 & 45 & \\
\hline Medium & 4 & 9 & \\
\hline Large & - & 1 & \\
\hline \multicolumn{4}{|l|}{ DOF } \\
\hline Discreet & - & - & \multirow[t]{4}{*}{0.966} \\
\hline Small & 37 & 38 & \\
\hline Medium & 43 & 41 & \\
\hline Large & 20 & 21 & \\
\hline \multicolumn{4}{|l|}{ Widest Occlusal Fossa } \\
\hline Distal & 94 & 95 & \multirow[t]{3}{*}{0.118} \\
\hline Mesial & - & 3 & \\
\hline Symmetrical & 6 & 2 & \\
\hline \multicolumn{4}{|c|}{ Occlusal fossa closer to the lingual surface } \\
\hline Distal & 53 & 67 & \multirow[t]{3}{*}{0.077} \\
\hline Mesial & 3 & 4 & \\
\hline Symmetrical & 44 & 29 & \\
\hline \multicolumn{4}{|c|}{ Proximal surface with the largest buccolingual dimensic } \\
\hline Distal & 95 & 94 & \multirow[t]{3}{*}{1.000} \\
\hline Mesial & 3 & 4 & \\
\hline Symmetrical & 2 & 2 & \\
\hline \multicolumn{4}{|l|}{ Groove from MOF } \\
\hline Absent & 68 & 61 & \multirow[t]{2}{*}{0.301} \\
\hline Present & 32 & 39 & \\
\hline \multicolumn{4}{|l|}{ Groove from DOF } \\
\hline Absent & 91 & 92 & \multirow[t]{2}{*}{0.800} \\
\hline Present & 9 & 8 & \\
\hline
\end{tabular}

observed that there was no statistically significant association between the observed features and sex in 44 and 34 $(\mathrm{p}>0.05)$.

From the 200 analyzed teeth, most presented DOF as the widest fossa, (94.5\%), as well as the distal surface constituted the proximal surface with the largest buccolingual dimension (94.5\%) (-Fig. 1).

When the occlusal fossa located closest to the lingual surface was evaluated, it was observed that in $60 \%$ of the examined teeth, the DOF occupied this position (-Fig. 1). In $36.5 \%$, MOF and DOF occupied a symmetrical position, and in 3.5\% MOF was closer to the lingual surface.

Regarding the grooves from the occlusal fossae, the groove from MOF (MOF groove) was more frequent (35.5\%) compared with the groove from DOF (DOF groove) (8.5\%), with no 


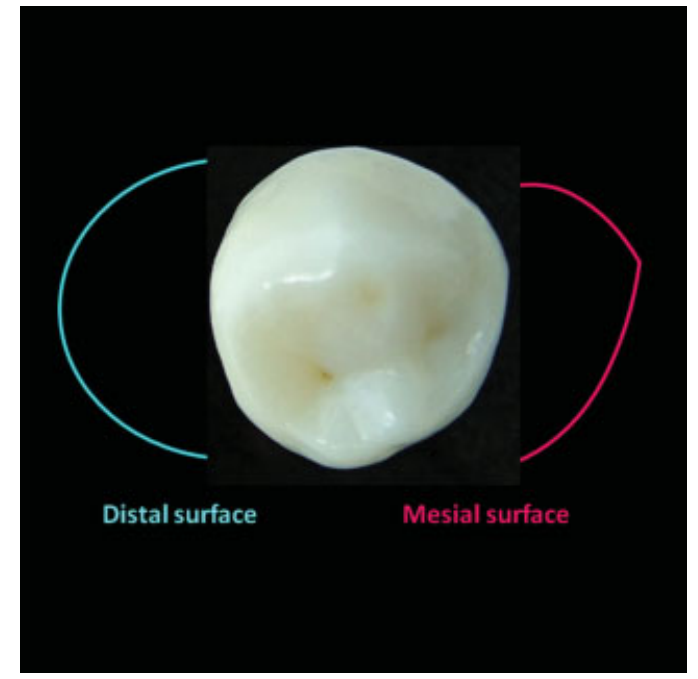

Fig. 1 Occlusal surface of a mandibular first premolar. MOF and DOF with different sizes. DOF is the widest one. Distal surface presenting the largest buccolingual dimension and a rounded configuration.

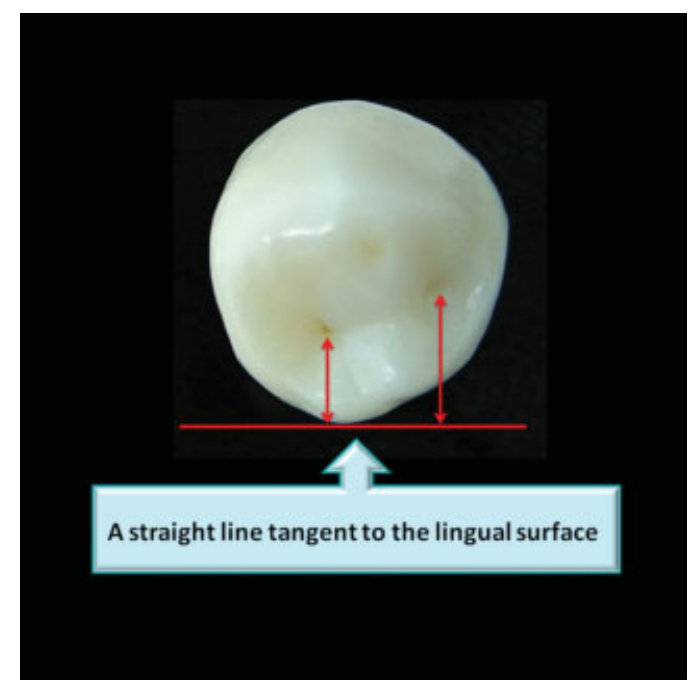

Fig. 2 Occlusal surface of a mandibular first premolar. DOF located closer to the line tangent to the lingual surface.

statistically significant difference between them $(p=1.0)$, and in most of the teeth, the grooves were absent.

There was no significant association between the groove from MOF and the size of MOF $(p=0.323)$, and no association between the groove from DOF and the size of DOF $(p=0.840)$.

When the occlusal fossa located closest to the lingual surface was the DOF, the groove from MOF was generally absent $(p=0.004)$. However, there was no significant association between the presence and absence of the groove from DOF, and the occlusal fossa located closest to the lingual surface $(p=0.504)$.

There was a statistical significant association between the sizes of the mesial and distal occlusal fossae $(p<0.001)$. The distal occlusal fossae were generally larger than the mesial fossae.
Table 2 Frequencies of evaluated anatomical features according to the tooth $(44 \times 34)$ showing the coincidences in the same individual

\begin{tabular}{|c|c|c|c|c|c|}
\hline \multirow{2}{*}{$\begin{array}{l}\text { Anatomical } \\
\text { Features (44) } \\
\text { MOF }\end{array}$} & \multicolumn{4}{|l|}{34} & \multirow[t]{2}{*}{$\mathrm{k}^{*}$} \\
\hline & Discreet & Small & Medium & Large & \\
\hline Discreet & 32 & 9 & - & 1 & \multirow[t]{4}{*}{0.4953} \\
\hline Small & 13 & 35 & 6 & - & \\
\hline Medium & - & 1 & 3 & - & \\
\hline Large & - & - & - & - & \\
\hline DOF & Discreet & Small & Medium & & \\
\hline Discreet & - & - & - & - & \multirow[t]{4}{*}{0.6225} \\
\hline Small & - & 27 & 10 & - & \\
\hline Medium & - & 11 & 27 & 5 & \\
\hline Large & - & - & 4 & 16 & \\
\hline $\begin{array}{l}\text { Widest } \\
\text { Occlusal } \\
\text { Fossa }\end{array}$ & Distal & Mesial & Symmetrical & & \\
\hline Distal & 90 & 2 & 2 & & \multirow[t]{3}{*}{0.0639} \\
\hline Mesial & - & - & - & & \\
\hline Symmetrical & 5 & 1 & - & & \\
\hline $\begin{array}{l}\text { Occlusal } \\
\text { fossa closer } \\
\text { to the lingual } \\
\text { surface }\end{array}$ & Distal & Mesial & Symmetrical & & \\
\hline Distal & 48 & 1 & 4 & & \multirow[t]{3}{*}{0.4920} \\
\hline Mesial & - & 2 & 1 & & \\
\hline Symmetrical & 19 & 1 & 24 & & \\
\hline $\begin{array}{l}\text { Proximal } \\
\text { surface } \\
\text { with the } \\
\text { largest } \\
\text { dimension }\end{array}$ & Distal & Mesial & Symmetrical & & \\
\hline Distal & 91 & 3 & 1 & & \multirow[t]{3}{*}{0.3715} \\
\hline Mesial & 2 & 1 & - & & \\
\hline Symmetrical & 1 & - & 1 & & \\
\hline $\begin{array}{l}\text { Groove } \\
\text { from MOF }\end{array}$ & Absent & Present & & & \\
\hline Absent & 54 & 14 & & & \multirow[t]{2}{*}{0.5439} \\
\hline Present & 7 & 25 & & & \\
\hline $\begin{array}{l}\text { Groove } \\
\text { from DOF }\end{array}$ & Absent & Present & & & \\
\hline Absent & 86 & 5 & & & \multirow[t]{2}{*}{0.2931} \\
\hline Present & 6 & 3 & & & \\
\hline
\end{tabular}

\section{Discussion}

In the discipline of Anatomy at São Paulo State University (UNESP), School of Dentistry, Araraquara, the methodology used to teach Dental Anatomy is based on direct observation of natural teeth, visualizing the general and specific features of each tooth. Other complementary methodologies such as macro models, dental sculpture and computer-assisted learning programs can be used. However, all these methodologies require knowledge of the specific anatomical features of each tooth. The purpose is that the student understands that knowing these features is important to 
Table 3 Frequency of anatomical features observed in 44 and 34 according to sex

\begin{tabular}{|c|c|c|c|c|c|c|}
\hline & \multicolumn{2}{|l|}{44} & & \multicolumn{3}{|l|}{34} \\
\hline & \multicolumn{2}{|l|}{ Sex } & & \multicolumn{3}{|l|}{ Sex } \\
\hline $\begin{array}{l}\text { Anatomical } \\
\text { Features }\end{array}$ & Female & Male & $\mathrm{p}$ & Female & Male & $\mathrm{p}$ \\
\hline \multicolumn{7}{|l|}{ MOF } \\
\hline Discreet & 34 & 8 & \multirow[t]{4}{*}{1.000} & 37 & 8 & \multirow[t]{4}{*}{0.852} \\
\hline Small & 43 & 11 & & 35 & 10 & \\
\hline Medium & 3 & 1 & & 7 & 2 & \\
\hline Large & - & - & & 1 & - & \\
\hline \multicolumn{7}{|l|}{ DOF } \\
\hline Discreet & - & - & \multirow[t]{4}{*}{0.196} & - & - & \multirow[t]{4}{*}{0.394} \\
\hline Small & 31 & 6 & & 29 & 9 & \\
\hline Medium & 31 & 12 & & 32 & 9 & \\
\hline Large & 18 & 2 & & 19 & 2 & \\
\hline \multicolumn{7}{|c|}{ Widest Occlusal Fossa } \\
\hline Distal & 74 & 20 & \multirow[t]{3}{*}{0.597} & 75 & 20 & \multirow[t]{3}{*}{1.000} \\
\hline Mesial & - & - & & 3 & - & \\
\hline Symmetrical & 6 & - & & 2 & - & \\
\hline \multicolumn{7}{|c|}{ Occlusal fossa closer to the lingual surface } \\
\hline Distal & 42 & 11 & \multirow[t]{3}{*}{0.132} & 52 & 15 & \multirow[t]{3}{*}{0.516} \\
\hline Mesial & 1 & 2 & & 3 & 1 & \\
\hline Symmetrical & 37 & 7 & & 25 & 4 & \\
\hline \multicolumn{7}{|c|}{ Proximal surface with the largest buccolingual dimension } \\
\hline Distal & 76 & 19 & \multirow[t]{3}{*}{0.681} & 75 & 19 & \multirow[t]{3}{*}{1.000} \\
\hline Mesial & 2 & 1 & & 3 & 1 & \\
\hline Symmetrical & 2 & - & & 2 & - & \\
\hline \multicolumn{7}{|c|}{ Groove from MOF } \\
\hline Absent & 55 & 13 & \multirow[t]{2}{*}{0.957} & 48 & 13 & \multirow[t]{2}{*}{0.682} \\
\hline Present & 25 & 7 & & 32 & 7 & \\
\hline \multicolumn{7}{|c|}{ Groove from DOF } \\
\hline Absent & 72 & 19 & \multirow[t]{2}{*}{0.793} & 72 & 20 & \multirow[t]{2}{*}{0.352} \\
\hline Present & 8 & 1 & & 8 & - & \\
\hline
\end{tabular}

establish the function, and they must be accurately reproduced in the patient.

Therefore, a poor contour, the absence of a groove, and a ridge out of position would compromise the function. ${ }^{12}$

In this study, we evaluated the occlusal features of the first mandibular premolar, because it is considered to be one of the most complex teeth, and students present difficulties in identifying it, particularly in relation to the determination of the hemi-arch.

It was verified that teeth 34 and 44 were not symmetrical in the same individual. Morphodifferentiation of teeth is clearly under genetic control, but the extent to which environmental factors can influence the process is unknown. Different teeth have characteristic occlusal topographies, and the variance in these topographies can be measured and used to determine the relative similarity between individuals. Heredity estimations revealed that genetic factors strongly influence occlusal morphology of mandibular primary first molars. ${ }^{16}$ According to Consolaro, epigenetics may explain why teeth of the same patient are not exactly the same on both sides. The genetic information that DNA carries is to develop teeth bilaterally equal. However, it does not happen due to the action of environmental features. ${ }^{17}$

The occlusal surface of the first mandibular premolar presents an ovoid form, ${ }^{11,12,18}$ frequently with the presence of two cusps, buccal and lingual, which are almost always united by an enamel ridge, which limits a fossa on each side (mesial and distal occlusal fossae). ${ }^{12,19,20}$

Our results showed that the widest occlusal fossa was the distal. According to Figún and Garino, even though the occlusal fossae are irregularly arranged, the distal fossa is the widest one. ${ }^{11}$ Some other authors reported that the DOF is the widest one. ${ }^{12,18}$ Other authors ${ }^{10,19,20}$ did not mention whether there were differences between the occlusal fossae.

According to our results, the distal surface presented the largest buccolingual dimension, and it presented a rounded configuration, whereas the mesial surface had a pointed contour. Figun and Garino (2003) also verified that the distal segment is the largest portion of the occlusal surface, and the mesial segment presents a large slope and a small dimension. ${ }^{11}$ Pagano et al. $(1965)^{18}$ reported that the occlusal surface presents a large/moderate reduction of the mesiolingual segment; the convex lingual surface is continuous with the contact surface and a large buccolingual dimension of the distal surface. ${ }^{18}$

The mesial surface presenting the largest size compared with the distal surface is considered to be one of the anatomical features, which is common to all teeth. Therefore, it was verified that the first mandibular premolar presents an exception to this rule, i.e., it presents the distal surface larger than the mesial one. The anatomy professor should point out this issue during the Dental Anatomy classes to improve the identification of the hemi-arch, and also the reconstruction of this tooth during oral rehabilitation procedures.

Besides the DOF being the widest, we also verified that it is the one which is located closest to the lingual surface. We observed only two authors who reported that the distal fossa is located closer to the lingual surface. ${ }^{11,12}$

The groove from MOF frequently continues to the lingual surface of the tooth. ${ }^{12,20}$ In our study, the groove from MOF was also the most frequent compared with the groove from DOF, though with no statistically significant difference between them. According to Pagano et al., ${ }^{18}$ there are some different situations related to the occlusal grooves: grooves from DOF, short grooves from MOF and DOF, or mesiolingual groove crossing the mesial marginal ridge. ${ }^{18}$

We observed that the grooves toward the lingual surface from MOF and DOF were not present in most individuals. Nevertheless, Madeira and Rizzolo reported that it is rarely absent. $^{12}$

Considering the results confirmed by statistical tests, we determined the most reliable criteria for the identification of the proximal surfaces of the first mandibular premolars, which will probably improve the individual study of these teeth during Dental Anatomy classes. 


\section{Conclusion}

According to the results, the following criteria were determined to identify the proximal surfaces of the mandibular first premolar:

- The distal occlusal fossa will be considered the largest occlusal fossa;

- The distal surface will be considered the proximal surface presenting larger buccolingual dimension and a rounded shape.

The occlusal fossa located closer to the lingual surface can also be evaluated, being considered the distal fossa. However, this feature should be considered the last of the three indicated criteria, because it generates a greater degree of error regarding the others.

\section{References}

1 Chun KJ, Yoo OS, Won YY, Lee JY. Morphological study and stress analysis of Korean Mandibular second premolar. Int J Precis Eng Manuf 2009;10(03):141-145 Doi: 10.1007/s12541009-0059-3

2 Obrez A, Briggs C, Buckman J, Goldstein L, Lamb C, Knight WG. Teaching clinically relevant dental anatomy in the dental curriculum: description and assessment of an innovative module. J Dent Educ 2011;75(06):797-804

3 Bernardino R Junior, Lucas BL, Borges DP, Souza AC. Primeiro prémolar inferior trirradiculado: um relato de caso. Biosci J 2007;23 (04):104-107

4 Buchaim RL, Andreo JC, Rodrigues A, et al. Multidisciplinary approach in the teaching of dental sculpture and anatomy. Int J Morphol 2014;32(02):399-403

5 Siéssere S, Vitti M, de Sousa LG, Semprini M, Regalo SCH. Educational material of dental anatomy applied to study the morphology of permanent teeth. Braz Dent J 2004;15(03):238-242 Doi: 10.1590/S0103-64402004000300014
6 Bogacki RE, Best A, Abbey LM. Equivalence study of a dental anatomy computer-assisted learning program. J Dent Educ 2004; 68(08):867-871

7 Jaffar AA. YouTube: An emerging tool in anatomy education. Anat Sci Educ 2012;5(03):158-164 Doi: 10.1002/ase.1268

8 Cleghorn BM, Christie WH, Dong CC. Anomalous mandibular premolars: a mandibular first premolar with three roots and a mandibular second premolar with a C-shaped canal system. Int Endod J 2008;41(11):1005-1014 Doi: 10.1111/j.1365-2591.2008.01451.x

9 Kraus BS, Furr ML. Lower first premolars. I. A definition and classification of discrete morphologic traits. J Dent Res 1953;32 (04):554-564

10 Della Serra O, Ferreira FV. Anatomia dental. São Paulo: Artes Médicas; 1981:334

11 Figún ME, Garino RR. Anatomia odontológica funcional e aplicada. Porto Alegre. Art Med 2003; $\cdots: 532$

12 Madeira MC. RIZZOLO RJC. Anatomia do dente. São Paulo: Sarvier; 2016:169

13 Dotto SR, Pagliarin CML, Carvalho MGP, Travassos RMC, Rosa RA. Tratamento endodôntico de pré-molar inferior com três condutos radiculares: relato de caso clínico. Rev Endodontia Pesquisa Ensino On Line 2007;3(06):1-7

14 Canger EM, Kayipmaz S, Celenk P. Bilateral dens invaginatus in the mandibular premolar region. Indian J Dent Res 2009;20(02): 238-240 Doi: 10.4103/0970-9290.52887

15 Girón G, Gómez P. MORALES L, LEÓN M, MORENO F. Rasgos morfológicos y métricos dentales coronales de premolares superiores e inferiores en escolares de tres instituciones educativas de Cali, Colombia. Int J Morphol 2009;27(03):913-925 Doi: 10.4067| S0717-95022009000300044

16 Su CY, Corby PM, Elliot MA, et al. Inheritance of occlusal topography: a twin study. Eur Arch Paediatr Dent 2008;9(01):19-24 Doi: $10.1007 / \mathrm{BF} 03321591$

17 Consolaro A. O gene e a epigenética: as características dentárias e maxilares estão relacionadas com fatores ambientais ou Os genes não comandam tudo! ou O determinismo genético acabou? Rev Dent Press Ortodon Ortop Facial 2009;14(06):14-18 Doi: 10.1590/ S1415-54192009000600003

18 Pagano JL, Carbó RAR, Ramón A. Anatomía dentária. Buenos Aires: Mundi; 1965:664

19 Picosse M. Anatomia dentária. São Paulo: Sarvier; 1977:294

20 Sicher H, Dubrul E. Anatomia oral. São Paulo: Artes Médicas; 1991 